\title{
The Mystical Experience and Its Neural Correlates
}

\author{
Marjorie Woollacott, $\mathrm{PhD}^{1}$, and Anne Shumway-Cook, $\mathrm{PhD}^{2}$ \\ ${ }^{1}$ University of Oregon \\ ${ }^{2}$ University of Washington
}

\begin{abstract}
Despite their different etiologies, three types of spiritually transformative experiences (STEs) - near-death experiences, psilocybin experiences, and meditative experiences of cosmic consciousness-appear to have attributes that are common to a broad range of mystical experiences, including an experience of expanded awareness. In addition, all three appear to be associated with profound and lasting transformations in the lives of experiencers. Finally, these three experiences appear to share some common neural correlates. In this article, we discuss similarities in case studies of these STEs, in data from controlled clinical research studies on their transformative effects, as well as from neurophysiological data correlated with the occurrence of the STEs themselves. In all three STEs, research shows a reduction in neural activity in the major centers of the brain, including the Default Mode Network, the foundation of egoic stories involving the narrative related to oneself and the world in which one lives. It is proposed that during these STEs, reduced neural activity in areas of the brain that normally act as a filter or reducing valve mechanism opens the capacity to expanded awareness, which is associated with lasting transformation in the lives of experiencers.
\end{abstract}

KEYWORDS: near-death experience, meditation, psilocybin, default mode network, neurophysiology

Mystical experiences have been a topic of discussions of spirituality and transformation throughout human history (Stace, 1960; Wulff, 2014). The study of these experiences became part of modern psycho-

Marjorie Woollacott, PhD, is Professor Emerita of the Department of Human Physiology and Institute of Neuroscience, University of Oregon, Eugene, OR. Her research background is in both rehabilitation and mind-body medicine. Anne Shumway-Cook, PhD, is Professor Emerita of the Department of Rehabilitation Medicine, University of Washington, Seattle, WA. Correspondence regarding this article should be send to Dr. Woollacott at email: mwool@uoregon.edu. 
logical investigation with the onset of research by a number of psychologists, including William James in the late 1800s and early 1900s (James, 1958; Myers, 1903). The extent to which mystical experiences have been studied may be partly due to their association with sudden, significant, and enduring changes in the lives of the people who had them. In other words, these experiences have been described as transformative.

Mystical experiences are defined by their common phenomenology and may be considered a subtype of the more general category of spiritually transformative experiences (STEs; Kason, 1994, 2019), defined by their transformative effects. Researchers have used two approaches to study STEs. In the first approach they focused on the STE itself, looking for a common core of phenomenological features that typify mystical experiences. In the second approach they focused on characterizing the transformation triggered by an STE. Despite the interest in studying these experiences, by their very nature they can be elusive and unpredictable, and thus only a few researchers have attempted to elucidate them through carefully controlled studies (Barrett \& Griffiths, 2018; Hood, 2009; Kelly et al., 2007).

Cumulative research on the phenomenology, aftereffects, and neural correlates of experiences that have mystical components has presented an opportunity for comparison of the experiences and for speculation about a possible single neural process underlying them all. In this article we will discuss research on three types of STE with mystical components, including data on both their core attributes and resultant transformation. We will explore the extent to which content and aftereffects of the three STEs reflect the content and aftereffects of mystical experiences. We will then compare research results on the neural correlates of the three STEs and, finding striking similarity, will present a theory about a single common neural process underlying all three.

\section{Relationships Between Three STEs with Mystical Components}

In this section, we begin with a classical definition and description of the characteristics of mystical experiences. We then discuss three types of STE: near-death experiences (NDEs), transcendent meditation experiences, and psilocybin experiences. For each of these three STEs, we begin with one or two case studies, each presenting a narra- 
tive of an individual exemplar of this type and our consideration of the extent to which it contained the attributes of mystical experience, indicated by bold type within the narrative. Following each case study, we present research data examining the transformational effects of the STE.

Mystical experience has been defined as a state of consciousness in which the person perceives a sense of unity-becoming one with all that exists (Watts, 1970). Walter Stace (1960) proposed seven core qualities common to all mystical experiences. He proposed that the variations in the accounts of mystical experiences in the writings of mystics of different backgrounds were due not to a difference in the core experience but, instead, to a difference in the cultural frame through which the mystics perceived those experiences (Barrett \& Griffiths, 2018; Stace, 1960). These core attributes include: (a) unity, (b) sacredness, (c) a noetic quality-insights into depths of truth unplumbed by the human intellect, (d) a deeply felt positive mood, (e) ineffability-no adequate way to express the subjective experience fully or accurately, (f) paradoxicality-including mutually exclusive states or concepts, and (g) a transcendence of time and space (Barrett \& Griffiths, 2017; Stace, 1960). It is important to note that the term mystical experience is not limited to a religious context but has been described outside the framework of any religious tradition by many persons undergoing an NDE, other STE, or psilocybin-induced experience (Barrett \& Griffiths, 2018; Hood et al., 1990).

\section{Near-Death Experience: Case Study and Research}

The following case study recounts the NDE of a medical practitioner, Bettina Peyton, described predominantly in her own words. Peyton was a materialist physician until she had an NDE during a high-risk cesarean section in the birth of her child. Partway through her procedure, while anesthetized, she heard her anesthesiologist's alarmed voice: "Her blood pressure is too low!" Peyton reported that his voice snapped her awake and that she became hyperaware (Woollacott, 2015). She wrote:

In the next instant, a strange stillness spread inside my chest, a hollow feeling. Something was missing-my heart beat. My heart had stopped. At the same time, my vision opened, and I discovered that I could see into the room. How amazing! The eyelids on my physical eyes had been taped shut to protect the corneas, yet by some other mechanism I could see perfectly clearly. (Woollacott, 2015, p. 109) 
Peyton watched her anesthesiologist slam his fist into a large red button on the wall, calling a cardiac arrest code that would result in the arrival of the hospital resuscitation team. Then her experience shifted with her perception of impending death. She said:

I see in my inner vision a vast darkness expanding behind me, at the backmost boundary of my mind ... My awareness reaches the edge of the precipice and I lean backwards, arching over the chasm of darkness below. Very naturally, I let myself fall, gliding downward in a graceful backward arc into the unknown ... I feel expanded, totally free ... Empty space surrounds me ... this space is absolutely empty. There is a sense of being suspended within a silent and dark void ... Consciousness is fully intact ... totally free, perfectly calm ...

Laced within the darkness, are innumerable particles of shimmering light ..., I soar with joy ... Resting, in a state of wonder, enveloped by the shimmering light. The silence is deep ... comforting ... I sense a pervasive presence within the light. The light is conscious ... intelligent, full of goodness. This shimmering void is full of pure awareness ... all knowledge ... all time ... all space ... I feel one with the void ... one with it all. Awestruck, ecstatic, serene ... All is perfect. (Woollacott, 2015, p. 110)

Then Peyton heard the words: "You must live!" A transcendent voice penetrated her peace, not in words, but in a quiet thunder. In the next instant, there was a tremendous rushing sound, accompanied by a sudden sensation of rapid swirling, and she was spinning downward in a contracting spiral. During the next minutes, she watched as the team successfully re-established her heartbeat, and Peyton knew in that moment that she would live. A few moments later, the nurse leaned over and whispered into Peyton's ear that her baby had lived; she had a healthy daughter.

When Peyton later regained consciousness, she was in the critical care unit; she couldn't talk, as she had a tube in her trachea, so she raised her hand to keep people from speaking and gestured to be given something for writing. Before anyone on the team could speak, Peyton wrote on a napkin, "I know I have a baby girl. I know my uterus is out. I know my heart stopped" (Woollacott, 2015, p. 113).

Peyton's experience included all seven of Stace's core attributes, specifically: (a) the sense of unity_-She felt one with the void, one with all; (b) sacredness and (c) noetic quality - a state of wonder, enveloped by the shimmering light; (d) deeply felt positive mood-awestruck, ecstatic, serene; (e) ineffability_-suspended within this silent and dark void; (f) paradoxicality_shimmering void full of pure awareness; and 
(g) the transcendence of time and space—all knowledge ... all time... all space).

In addition, her NDE resulted in a transformation characterized by a new understanding of the nature of consciousness and the interconnectedness of all beings and all reality. After her experience she began to study meditation, a practice that helped her recapture the transcendent state that characterized her NDE, and she shifted her medical career to hospice care, where she could help people in this life transition, as she perceived that end-of-life and NDEs have a common core.

Several researchers have published peer-reviewed articles describing studies of the mystical qualities and aftereffects of NDEs. An example is that of Janet Schwaninger and her colleagues at Washington University Medical Center in St. Louis, who examined mystical features of, and transformations after, experiences during cardiac arrest (Schwaninger et al., 2002). Of 174 patients who experienced cardiac arrest in this controlled prospective clinical study, 30 survived and were available to be interviewed. Of these, 11 reported an NDE (NDErs), and 19 reported no memory of an NDE (non-NDErs). Regarding mystical features of NDEs, Schwaninger and colleagues reported several, including a sense of cosmic unity (45\%), a deeply felt positive mood (peace; 100\%), ineffability (100\%), and a sense of infinite space (9\%). Regarding subsequent transformation, at 6 -month follow-up, 8 NDErs and 10 nonNDErs completed Kenneth Ring's (1984) 42-item Life Changes Questionnaire to assess self-perceived changes following survival of cardiac arrest. Each participant was asked to rate life changes on a scale from 1 (strongly increased) to 5 (strongly decreased). For all 42 items, NDErs reported a greater increase in the phenomenon than did nonNDErs, and in 26 of those cases, the difference was statistically significant $(p<.05)$. Table 1 shows selected statistically significant items - nine that we considered to be related to possible transformation in participants' interest in spirituality, sense of the sacredness of life, and sense of the value of self, others, and the planet.

Schwaninger et al.'s (2002) study was one among all peer-reviewed studies published through 2005 that Zingrone and Alvarado (2009) included in their critical review. They found the characteristics of mystical experiences to be common among NDE narratives. In a similar review of research on NDE aftereffects, Noyes et al. (2009) found longlasting transformation to be typical, including an enhanced sense of unity awareness and of love and joy. Subsequent peer-reviewed stud- 
Table 1 Life Changes After NDEs

\begin{tabular}{lccc}
\hline \multicolumn{1}{c}{ Item } & $\begin{array}{c}\text { NDErs } \\
(\boldsymbol{n}=\mathbf{8})\end{array}$ & $\begin{array}{c}\text { NonNDErs } \\
(\boldsymbol{n}=\mathbf{1 0})\end{array}$ & $\begin{array}{c}\text { Significant Differ- } \\
\text { ence ( } \boldsymbol{p} \text { value })\end{array}$ \\
\hline Desire to Help Others & 1.5 & 2.5 & .027 \\
Appreciation of Nature & 1.5 & 2.4 & .015 \\
Feelings of Self-Worth & 1.6 & 3.0 & .009 \\
Concern with Spiritual Matters & 1.6 & 2.5 & .030 \\
Ability to Express Love for Others & 1.4 & 2.5 & .025 \\
Insight into Problems of Others & 1.6 & 2.6 & .005 \\
Understanding of Others & 1.5 & 2.7 & .001 \\
Sense of Sacredness of Life & 1.4 & 2.8 & .001 \\
Inner Sense of God's presence & 1.3 & 2.7 & \\
\hline
\end{tabular}

Note. Adapted from Table III, Schwaninger et al., 2002.

ies have added to this evidence (Greyson \& Khanna, 2014; Khanna \& Greyson, 2014a, 2014b; Tassell-Matamua \& Steadman, 2017), strengthening the conclusion that the mystical experience and subsequent life transformation in Peyton's account was not an isolated case but, rather, was representative of many persons who have had NDEs.

\section{Meditation: Case Study and Research}

The following case study is the experience of Allen Smith, an MD, who worked as a researcher in anesthesiology before his mystical experience, which happened when he was 38 years old (https://www.aaps global.com/1999/03/07/4-my-experience-of-cosmic-consciousness/). Before the experience he was an academic researcher, scientist, and materialist. He said, "I was not interested in nor was I searching for any sort of transcendent or supernatural experience. I had no idea of what a mystical experience was." His mystical and meditative event occurred unexpectedly while he was alone one evening at his home in Oakland, California, and was watching a particularly beautiful sunset. 
He was sitting in an easy chair placed next to floor-to-ceiling windows that faced northwest. The experience began with some mild tingling at the base of the spine. He then noticed that the level of light in the room as well as that of the sky outside seemed to be increasing slowly. The light seemed to be coming from everywhere, not only from the waning sun. In fact, the sun itself did not give off a strong glare. He said, "Along with the light came an alteration in mood. I began to feel very good, then still better, then elated."

While this was happening, the passage of time seemed to become slower and slower. Eventually, the sense of time passing stopped entirely. Only the present moment existed. He entered an ecstatic state. He said:

The white light around me merged with the reddish light of the sunset to become one all enveloping, intense undifferentiated light field.

I merged with the light and everything became one unified whole. There was no separation between myself and the rest of the universe. To say that subject merged with object might be almost adequate as a description of the entrance into Cosmic Consciousness. All words or discursive thinking stopped. There was just a timeless, unitary state of being. Immediately following return to usual consciousness, I cried uncontrollably for about a half hour. I cried both for joy and for sadness, because I knew that my life would never be the same.

This experience had a major impact on the course of Smith's life. He had received a national prize for his research and had a grant funded for five years, but any interest he had in becoming a famous academician evaporated. He said, "My research seemed more like an interesting puzzle than work of immense importance to the world." He left his secure and successful university faculty position and supported himself as a part-time freelance clinician; after earning a degree in Consciousness Studies and Theology, he worked in medical ethics. He said, "I needed time to explore spirituality and to integrate the cosmic consciousness experience into my life."

Smith's mystical experience included all seven of Stace's (1960) core attributes, specifically: (a) the sense of unity-everything became one unified whole), (b) sacredness and (c) noetic quality-he merged with the light, (d) deeply felt positive mood-he entered an ecstatic state, (e) ineffability-words or discursive thinking stopped, (f) paradoxicality - he merged with the light, and (g) the transcendence of time and space-sense of time passing stopped entirely; only the present moment existed. In addition, his STE resulted in a transformation char- 
acterized by a new understanding of the nature of consciousness-a shift in worldview so powerful that he left his academic career in order to explore spirituality.

The second case study recounts the transcendent meditation experience of one of the authors, Marjorie Woollacott. During my PhD program I was trained as a materialist neuroscientist and, when I was 30 years old, had just accepted a professorship at a university in Virginia. That summer I had an experience in meditation that opened the door to an awareness of a dimension of reality I had never before encountered (Woollacott, 2015). My sister had invited me to a meditation retreat by an Indian meditation master. I was skeptical, but I decided to attend. The first morning of the retreat, participants were told that during the meditation session the swami would walk around the room and initiate each person there. This was described as a spiritual awakening. My scientific mind-set made me skeptical (Woollacott, 2015).

When the swami came to me, I felt his thumb and fingers right between my eyes and on the bridge of my nose. I said,

It was as if a tiny lightning bolt leapt from his fingers to a point between my eyes and down to the center of my chest, to my heart. Not the physical heart but parallel to the physical heart and more like a heart than my physical heart had ever been. I felt the energy from my heart radiate outward and fill my whole being and beyond. I experienced pure love pouring through me. I felt a connection with other living things that I had never felt before. My mind was still, and there was a new sense of wholeness, of integrity inside, which words cannot describe. Words went through my mind: I'm home, I'm home! My heart is my home. (Woollacott, 2015)

My experience, a spiritual awakening, contained many of the core attributes of a mystical experience including, (a) the sense of unity-I had an unprecedented feeling of connection with other living things, (b) sacredness - energy from my heart radiated and fill me whole being and beyond, (c) noetic quality - a new sense of wholeness, of integrity inside, (d) deeply felt positive mood-I experienced pure love pouring through me, (e) ineffability - inability to find words to describe my new sense of wholeness, of integrity, and (f) paradoxicality-as if a tiny lightning bolt leapt from his fingers to a point between my eyes and down to the center of my chest, to my heart.

What was most astonishing to me was the transformation that occurred after this spiritual experience. I said: 
Without any effort I made a surprising shift in my routine, beginning the morning after I returned. I got up at 5 a.m., spontaneously and meditated. It happened day after day, and is still present in my life. I did this with the awareness that just beneath my thoughts was a quiet ecstasy. Though it took me many years to truly integrate that mystical experience into my career, there were immediate effects on my life, including a sense of peace and well being, a loss of fear of death, and a sense of joy and love that was deeper than I had previously known. (Woollacott, 2015)

As was true for NDEs, much anecdotal evidence illustrates the mystical aspects of transformative meditation experiences. This evidence is bolstered by results of controlled research studies on meditation.

For example, Barbara Fredrickson and colleagues at the University of North Carolina examined changes in positive emotions associated with meditation. In this randomized, controlled study, 100 employees of a software corporation were trained in meditation over 7 weeks. Results, shown in Figure 1, indicated that, compared to a no-treatment control group, the meditation group showed a steady increase in positive emotions over the course of the training, including amusement, awe, contentment, gratitude, hope, interest, joy, love, and pride (Fredrickson et al., 2008).

Figure 1 Increases in Positive Emotions During the Course of Meditation Training
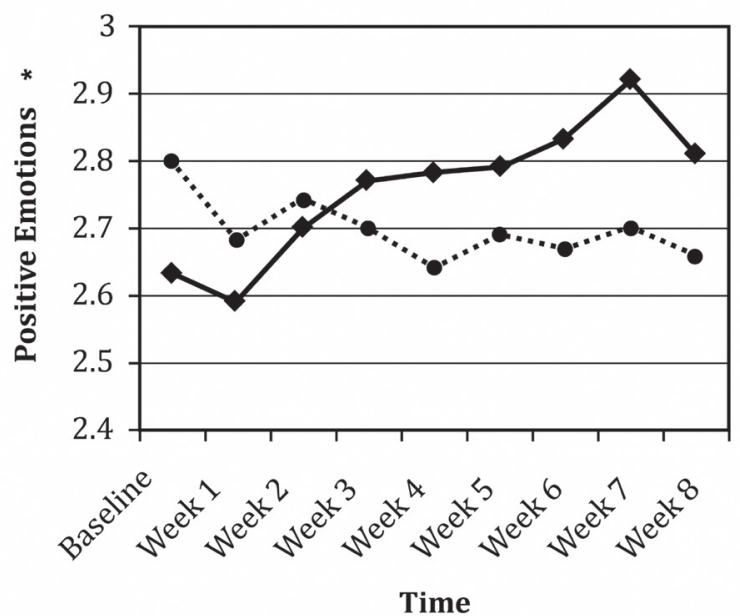

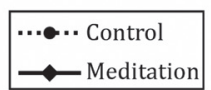

*Positive Emotions

Amusement

Awe

Contentment

Gratitude

Hope

Interest

Joy

Love

Pride

Note. Adapted from Fredrickson et al., 2008, Figure 2, p. 27. 
In addition, these positive emotions were linked to increases in a variety of personal resources, including self-acceptance and positive relations with others, resulting in a stronger sense of life satisfaction. Other studies have also shown that meditation increases compassion and the desire to help others who are suffering (Condon et al., 2013; Luberto et al., 2018; Ricard et al., 2014).

The data from anecdotes and research on both NDEs and meditation indicate that both phenomena have a transformative effect on many traits, including love and joy, as well a sense of increased connection with the rest of humanity. In the next section we address the last STE category: mystical experiences induced by the ingestion of psilocybin.

\section{Psilocybin: Case Study and Research}

The following case study is the experience of a man who participated in a study by Roland Griffiths, at Johns Hopkins University Medical Center (Barrett \& Griffiths, 2018). The research participant said:

In my mind's eye, I felt myself instinctively taking on the posture of prayer in my head. I was on my knees, hands clasped in front of me and I bowed to this force. I wasn't scared or threatened in any way. It was more about reverence. I was showing my respect. I was humbled and honored to be in this presence. This presence was a feeling, not something I saw or heard. I only felt it, but it felt more real than any reality I have experienced. And it was a familiar place too. One I had felt before. It was when I surrendered to this, that I felt like I let go. I was gone... or I should say this earthly part of me was. It was still on the couch in some sort of suspended animation awaiting my return. I was in the void. This void had a strange and indescribable quality to it in that there was nothing to it but this feeling of unconditional and undying Love. It felt like my soul was basking in the feeling of this space. I have no idea how long this lasted. Time and space did not exist there . . . it was all different manifestations of this Love feeling I found myself wrapped in. (Barrett \& Griffith, 2018, p. 397)

This man's narration of his experience suggests that it created a new connection with spirituality and a sense that this experience was more real than anything he had experienced before. There was a sense that the earthly part of him was gone and that he was much more than this earthly existence. He experienced a sense of unity and interconnectedness with all of life, with everything. Where he found 
himself in the experience, time and space did not exist; all that existed were a sense of unconditional and undying love.

This participant's mystical experience also included all seven of Stace's (1960) core attributes, specifically: (a) the sense of unity-he was in the void, (b) sacredness and (c) noetic quality-he bowed to this force, (d) deeply felt positive mood-feeling of unconditional and undying Love, (e) ineffability—had a strange and indescribable quality, (f) paradoxicality-felt more real than any reality he had previously experienced, and (g) transcendence of time and space-time and space did not exist there.

In addition to these data from a case study of one person's mystical experience under psilocybin, researchers conducting randomized controlled trials to examine the long-term effects of a single psilocybin dose have also observed transformation among participants. For example, Stephen Ross and colleagues from NYU Medical center performed a randomized controlled trial with terminal cancer patients to determine if psilocybin would reduce the depression and anxiety that patients experienced as a result of their cancer diagnosis and the prospect that their lives would end soon (Ross et al., 2016). This was a cross-over study: In the first session, participants received either psilocybin or a placebo, niacin, used as the control; then, about 7 weeks after session 1, the crossover session occurred, when participants in the control group received the psilocybin. At two weeks after the first dose, and again at 26 weeks after the second dose, participants from both groups completed the Persisting Effects Questionnaire to assess lasting effects of the drug trial with regard to four variables that are comparable to the aftereffects of mystical features we have previously discussed. Higher scores indicated a greater self-reported presence of the variable. The first-dose-niacin scores were compared to each of the other three sets of scores. Table 2 shows the results.

In addition to participants' reported positive changes from, and top rating of, the psilocybin experience, the authors stated that at 6.5 months post ingestion, $60-80 \%$ of the psilocybin groups continued to show reduced anxiety and depression. They concluded,

This pharmacological finding is novel in psychiatry in terms of a single dose of medication leading to immediate anti-depressant and anxiolytic effects with (e.g., weeks to months) clinical benefits. (Ross et al., 2016, p. 1175)

They also noted that the psilocybin experience decreased cancerrelated loss of hope and meaning and improved spiritual wellbeing, 
Table 2 Mean and Standard Error of Persisting Effects Questionnaire Scores (\% Maximum)

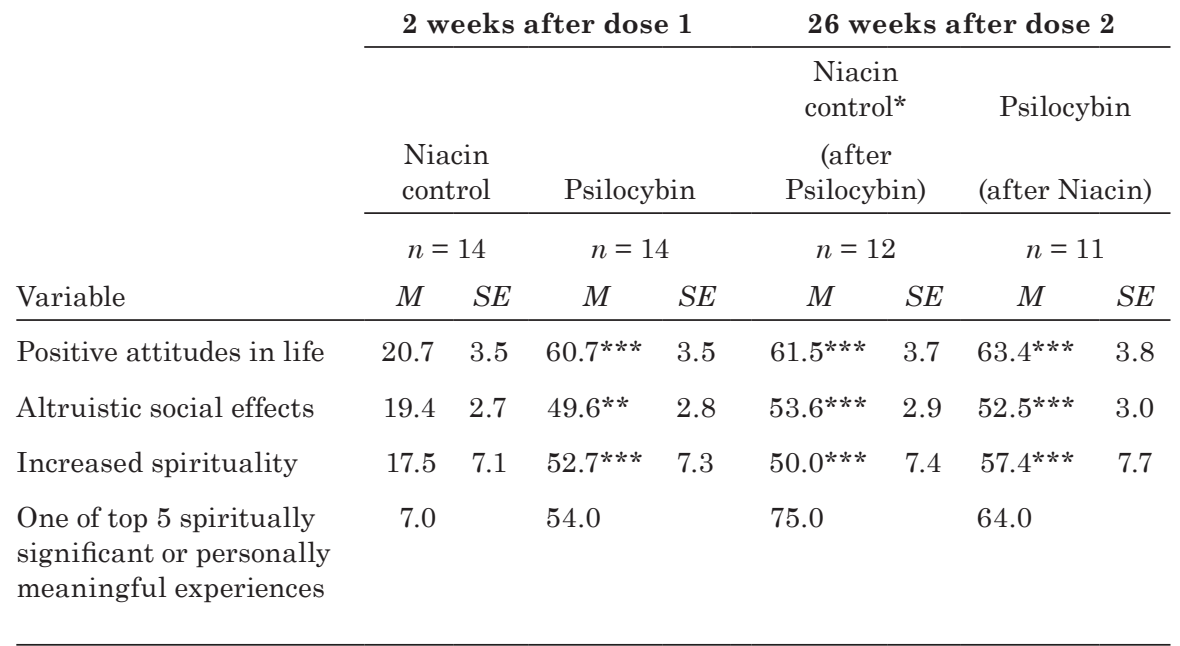

Note. Adapted from Ross et al., 2016, supplemental material.

* The 26-week post-dose data for the niacin group are similar to those for psilocybin because by this time the cross-over portion of the experiment had occurred and these participants had ingested psilocybin 6.5 months earlier; thus, they were reporting on persisting effects from the previous psilocybin experience.

$* * p<.01$

$* * * p<.001$

life satisfaction, and quality of life. Results from this study have been supported by similar research in other laboratories (Kraehenmann et al., 2015; Nicholas et al., 2018).

\section{Comparative Summary of Mystical Features in Three STEs}

Table 3 summarizes the core attributes that occurred in each of the case studies discussed in the previous sections, showing the similarities in characteristics of core mystical characteristics across the three types of experience.

Both the case studies and research evidence support the hypothesis that a similar mystical experience, including some but not all of Stace's (1960) core attributes, occurs during all three types of STENDE, meditation, and psilocybin experience-and is associated with a 
Table 3 Examples of Stace's Criteria for Mystical Experiences From the Four Case Studies

\begin{tabular}{|c|c|c|c|c|}
\hline $\begin{array}{l}\text { Stace mystical } \\
\text { experience } \\
\text { characteristic }\end{array}$ & $\begin{array}{l}\text { Case 1: } \\
\text { NDE }\end{array}$ & $\begin{array}{c}\text { Case 2: } \\
\text { Meditation }\end{array}$ & $\begin{array}{c}\text { Case 3: } \\
\text { Meditation }\end{array}$ & $\begin{array}{c}\text { Case 4: } \\
\text { Psilocybin }\end{array}$ \\
\hline Unity & $\begin{array}{l}\text { I feel one with } \\
\text { the void, one } \\
\text { with all }\end{array}$ & $\begin{array}{l}\text { everything } \\
\text { became one uni- } \\
\text { fied whole }\end{array}$ & $\begin{array}{l}\text { I felt a connec- } \\
\text { tion with other } \\
\text { living things } \\
\text { that I had never } \\
\text { felt before }\end{array}$ & I was in the void \\
\hline Sacredness & $\begin{array}{l}\text { enveloped by } \\
\text { the shimmering } \\
\text { light }\end{array}$ & $\begin{array}{l}\text { I merged with } \\
\text { the light }\end{array}$ & $\begin{array}{l}\text { energy from my } \\
\text { heart radiated } \\
\text { and fill my } \\
\text { whole being } \\
\text { and beyond }\end{array}$ & $\begin{array}{l}\text { I bowed to this } \\
\text { force }\end{array}$ \\
\hline Noetic quality & $\begin{array}{l}\text { a state of won- } \\
\text { der, enveloped } \\
\text { by the shimmer- } \\
\text { ing light }\end{array}$ & $\begin{array}{l}\text { I merged with } \\
\text { the light }\end{array}$ & $\begin{array}{l}\text { a new sense of } \\
\text { wholeness, of } \\
\text { integrity inside, } \\
\text { which words } \\
\text { cannot describe }\end{array}$ & $\begin{array}{l}\text { I bowed to this } \\
\text { force }\end{array}$ \\
\hline $\begin{array}{l}\text { Deep positive } \\
\text { mood }\end{array}$ & $\begin{array}{l}\text { awestruck, ec- } \\
\text { static, serene }\end{array}$ & $\begin{array}{l}\text { entered an } \\
\text { ecstatic state }\end{array}$ & $\begin{array}{l}\text { I experienced } \\
\text { pure love pour- } \\
\text { ing through me }\end{array}$ & $\begin{array}{l}\text { feeling of un- } \\
\text { conditional and } \\
\text { undying Love }\end{array}$ \\
\hline Ineffability & $\begin{array}{l}\text { suspended } \\
\text { within this } \\
\text { silent and } \\
\text { dark void }\end{array}$ & $\begin{array}{l}\text { words or discur- } \\
\text { sive thinking } \\
\text { stopped }\end{array}$ & $\begin{array}{l}\text { a new sense of } \\
\text { wholeness, of } \\
\text { integrity inside, } \\
\text { which words } \\
\text { cannot describe }\end{array}$ & $\begin{array}{l}\text { this void had } \\
\text { a strange and } \\
\text { indescribable } \\
\text { quality }\end{array}$ \\
\hline Paradoxicality & $\begin{array}{l}\text { shimmering } \\
\text { void is full of } \\
\text { pure awareness }\end{array}$ & $\begin{array}{l}\text { I merged with } \\
\text { the light }\end{array}$ & $\begin{array}{l}\text { as if a tiny } \\
\text { lightning bolt } \\
\text { leapt from his } \\
\text { fingers ... to } \\
\text { my heart }\end{array}$ & $\begin{array}{l}\text { it felt more } \\
\text { real than any } \\
\text { reality I have } \\
\text { experienced }\end{array}$ \\
\hline $\begin{array}{l}\text { Transcendence of } \\
\text { time and space }\end{array}$ & $\begin{array}{l}\text { all knowledge } \\
\ldots \text {. all time ... } \\
\text { all space }\end{array}$ & $\begin{array}{l}\text { sense of time } \\
\text { passing stopped } \\
\text { entirely; only } \\
\text { the present mo- } \\
\text { ment existed }\end{array}$ & - & $\begin{array}{l}\text { time and space } \\
\text { did not exist } \\
\text { there }\end{array}$ \\
\hline
\end{tabular}


profound transformation that includes a strong increase in a sense of unity and connectedness, love, compassion, and joy. In addition, these changes result in a remarkably long-lasting sense of improved wellbeing and life satisfaction. In the next section of this article, we address a most intriguing question: whether a common neural correlate underlies these STEs and the remarkable transformations that follow them.

\section{Neural Correlates of Experiences with Mystical Features}

In this section we review research on the specific brain activity associated with meditation, psilocybin ingestion, and NDEs, comparing their results. We then propose a theory about a common neural correlate to the mystical content and transformational aftereffects of these three STEs.

Research examining neural activity during various behavioral states suggests that an individual's normal mental state is highly influenced by the wide-ranging narrative or Mind Wandering Network of the brain, described by many as the Default Mode Network (DMN) of the brain. The DMN is considered by many neuroscientists to be the source of the ego-the notion of self and an identification with the thoughts, emotions, and roles one plays in the world (Carhart-Harris $\&$ Friston, 2010). Figure 2 illustrates activation patterns during brain scans when people are simply relaxing, letting their mind go where it wants. It illustrates components of the DMN including areas of the medial prefrontal cortex, the posterior cingulate cortex, the precuneus, the inferior parietal lobe, and the lateral temporal cortex.

Neuroscientists such as Griffiths (Barrett \& Griffiths, 2018) have suggested that transformative mystical experiences that produce a sense of unity and interconnectedness are associated with egodissolution, defined as a sense that the border between one's self and the external world is dissolving. His research has demonstrated a high correlation between a sense of unity consciousness and reduced activity and decoupling of the DMN. Other researchers of neural processes underlying meditation have found similar results (Brewer et al., 2011; Pagnoni et al., 2008). For example, Judson Brewer and his colleagues, from the Department of Psychiatry at Yale University School of Medicine, showed significant reductions in two primary nodes of the DMN during three types of meditation: choiceless awareness-simply being present to what is happening in the moment, loving kindness, 
Figure 2 Components of the Default Mode Network of the Brain

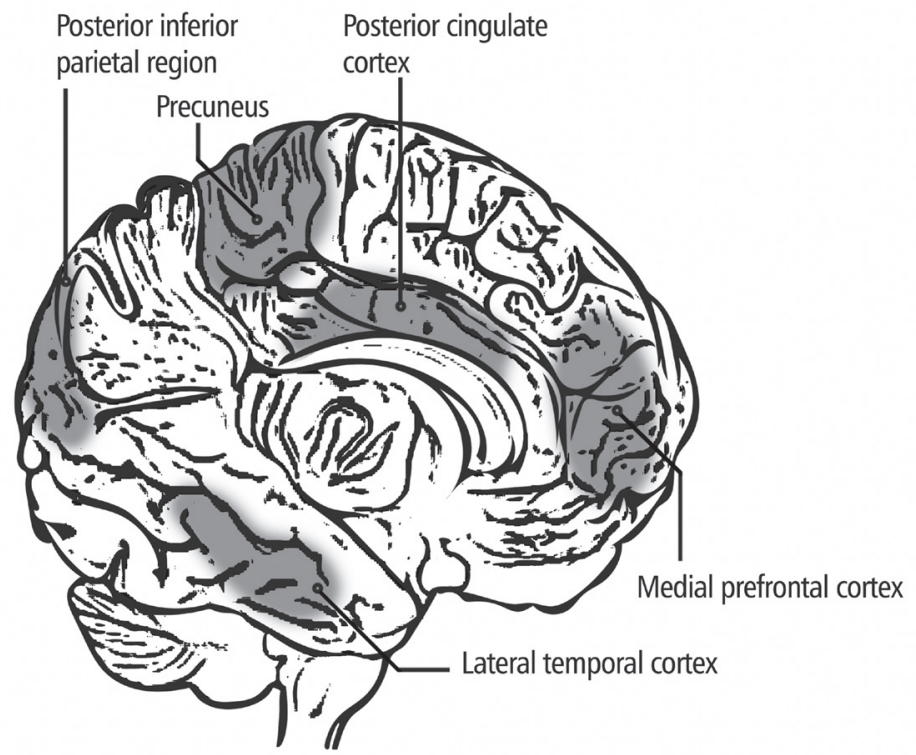

Note. Adapted from Ricard et al., 2014.

and concentrative meditation - focusing on the breath (Brewer et al., 2011). They compared functional magnetic resonance imaging scans of brain activity in the DMN in advanced meditators and control participants who were new to meditation. As Figure 3 shows, they found that the main nodes of the DMN were relatively deactivated during all three types of advanced meditators compared to controls. In addition, the functional connectivity of other parts of the brain involved in cognitive control was increased in meditators compared to controls, both in their resting state and during meditation. These data suggest that the brain truly becomes quieter in meditation; it becomes quite still as the narrative part of the brain is silenced.

We hypothesize that during mystical meditation experiences, a disruption of the DMN stills the narrative mind, thus enabling an expanded awareness of subtler perceptions that are normally filtered out. Interestingly, a number of studies on psilocybin's effects on brain networks offer data to support this hypothesis and show effects similar to those of meditation (Barrett \& Griffiths, 2018; Carhart-Harris et al., 2012; Thomas et al., 2017). For example, Figure 4, from re- 
Figure 3 Reductions in Default Mode Network Brain Activity for Meditators vs. Control Participants During Meditation

A

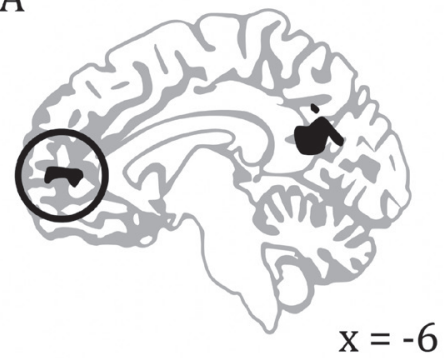

B
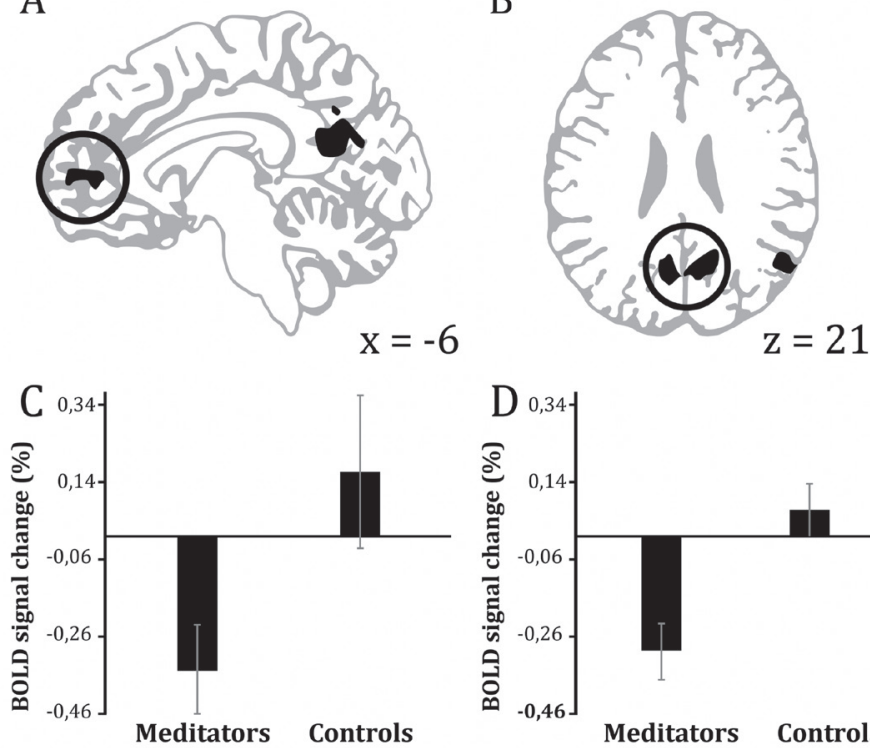

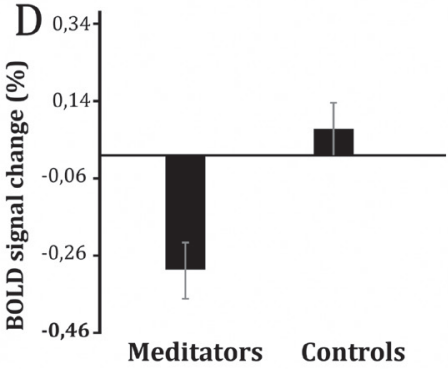

Note. Adapted from Brewer et al., 2011.

Reductions are indicated by blackened areas of the brain. A and B: Reduced activations in the left mPFC (medial prefrontal cortex) and PCC (posterior cingulate cortex/precuneus. C and D: Average percent signal change $( \pm S D)$ during meditation in the $m P F C$ and $P C C$ in meditators vs. control participants.

search by Barrett and Griffiths (2018) at Johns Hopkins University Medical Center, shows similar deactivations in the medial DMN during meditation and psilocybin ingestion.

The top of the figure shows the two areas of the brain involved in this network, for reference. The middle of the figure shows deactivation of the network with psilocybin studies, and the lower part of the figure shows these same deactivation patterns with meditation.

Thus, research demonstrates very similar neural effects with psilocybin and meditation, both reducing the activity in the DMN. This reduction in the Default Mode of brain activity is directly correlated with an increased sense of unity consciousness and ego-dissolution. Though brain imaging studies are not feasible when an NDE occurs during a cardiac arrest, available EEG data show that the entire cor- 
Figure 4 Similar Deactivations in the DMN in Two Studies of the Effects of Meditation and Psilocybin

Medial Prefrontal Cortex

Posterior Cingulate Cortex
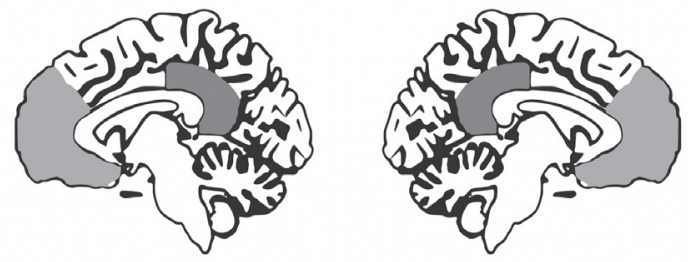

Deactivations in CBF and BOLD During Psilocybin Effects (Carhart-Harris etal., 2012)

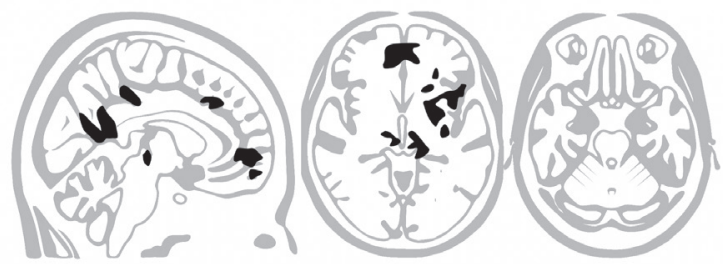

Deactivations in BOLD During Meditation (Brewer etal., 2011)
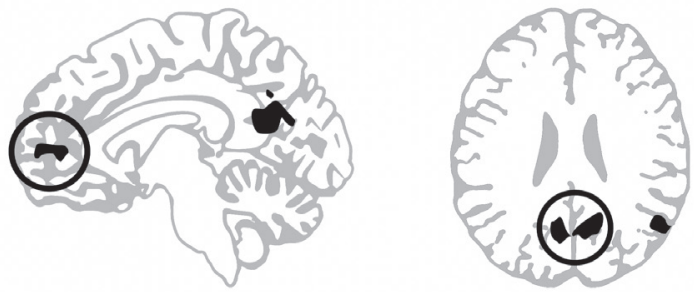

Note. Adapted from Barrett \& Griffiths, 2018, Figure 7, p. 416.

The top level of the figure shows the locations of the medial prefrontal cortex and posterior cingulate cortex (light and dark grey areas)—two areas of the brain involved in the DMN. The center of the figure shows regions in the medial DMN, where intravenous injection of psilocybin resulted in a decrease in blood-oxygenation-level-dependent (BOLD) activity (black areas). The lower level of the figure shows regions in the medial DMN where decreases in BOLD data were observed during meditation. 
tex, including the DMN, is deactivated (van Lommel et al., 2001). In the next section, we present our theory of a single process underlying the convergence of data from case study, research, and brain imaging regarding the mystical features of the three STEs addressed in this article.

\section{Filter Theory and Mystical Experiences}

The concept of filtering within the brain is not new. Filtering serves to limit incoming information in order to reduce the processing demands on the brain. For example, neuroscientists have identified a number of networks in the brain that serve as attentional filters, reducing the overwhelming amount of information constantly bombarding the senses. Given the brain's limited processing capability, attentional filters that limit information are essential to the ability to function effectively in daily life (Broadbent, 1958; Kelly et al., 2007).

The DMN serves as another filter, as it habitually restricts awareness and maintains attention on the ongoing self-referential narratives of the brain. The DMN serves as a filter, or reducing valve mechanism, that normally confines awareness within limits defined by the needs of everyday life (Kastrup \& Kelly, 2018; Swanson, 2018). We propose that during at least the three STEs we have addressed in this article, when the DMN is stilled, filtering is reduced, resulting in expanded awareness and capacity to perceive mystical phenomena. A number of researchers (Parnia, 2014; Sabom, 1982; Sartori, 2008; van Lommel et al., 2001) have documented that during cardiac arrest, despite a flatlined EEG, some individuals experience perceptions outside of the body. One explanation for this phenomenon is that during this type of NDE, filters that normally block out expansive states of consciousness that go beyond the experience of the five senses are no longer active.

We understand that this proposal would be highly suspect among neuroscientists holding a materialist view that the brain is the source of all mental and perceptual activity. The current view from a materialist perspective holds that altered activity in the brain, for example, during cardiac arrest and associated NDEs, is associated with hallucinations caused by a lack of oxygen and excess transmitter release from dying neurons (for a review, see Kelly et al., 2007). An individual with this view could instead propose, as do Robin Carhart-Harris et al. (2012), that decreased activity and connectivity in the brain's key connector hubs, including the Default Mode Network, enables what 
they call a state of unconstrained cognition. Proponents of this view would suggest that other parts of the brain may be freed to interact in novel ways and contribute to a mystical experience including that of unitive consciousness.

We find a number of flaws in this hypothesis, in which its proponents propose that either altered normal or pathological brain activity is the cause of mystical experiences. As psychiatrist and veteran NDE researcher Bruce Greyson (2003) noted in an excellent rebuttal to this argument related to NDEs:

The paradoxical occurrence of heightened, lucid awareness and logical thought processes during a period of impaired cerebral perfusion raises particularly perplexing questions for our current understanding of consciousness and its relation to brain function. As prior researchers have concluded, a clear sensorium and complex perceptual processes during a period of apparent clinical death challenge the concept that consciousness is localized exclusively in the brain. (p. 275)

The filter hypothesis, as it is defined here, is an alternative to the traditional view proposed by Carhart-Harris; however, it is possible that elements of both theories contribute to mystical experience. The reduction or cessation of brain activity in networks such as the DMN both frees other parts of the brain to interact in novel ways and reduces the filtering mechanisms of the brain, enabling a more expansive consciousness to be perceived.

Having looked at the data demonstrating reductions in brain activity, specifically in the DMN, in the three types of STEs presented here, we propose a possible model that reflects what happens when an individual shifts from the normal DMN and egoic narrative that normally dominates waking consciousness to a mystical experience of cosmic consciousness. This model is shown in Figure 5.

In the normal waking state, dominated by the $\mathrm{DMN}$, the capacity to experience nonlocal cosmic consciousness appears to be reduced. This is represented by a type of filter that limits access to awareness of subtler perceptions. Although most scientists agree that such a filter exists as part of normal human brain activity, including the DMN (Broadbent, 1958), there is no agreement as to the role this type of filter plays in mystical experience.

We propose that when activity in the DMN is reduced-as during meditation or psilocybin experiences—or removed-as during NDEs, the filter is also reduced or eliminated, and there is enhanced capacity to experience nonlocal (cosmic) consciousness. In Figure 5, this 
Figure 5 Proposed Model of Shifts From Normal Waking Awareness to an NDE/Meditation/Psilocybin Mediated Awareness

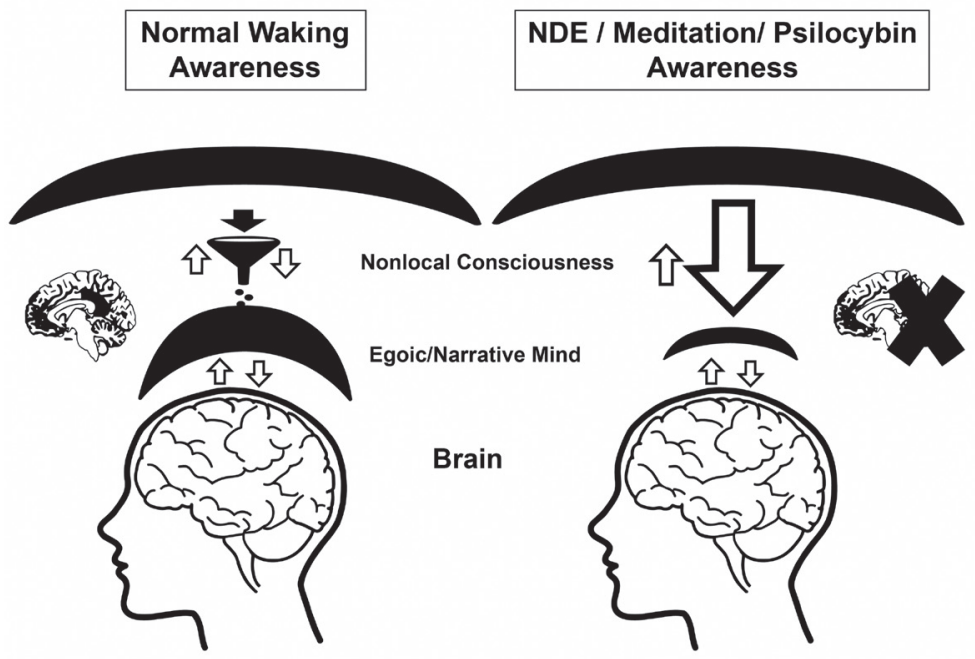

process is represented by the reduced mental activity and increased input flowing from nonlocal consciousness down to the mind and brain (large arrow). When this process occurs, the person experiences a sense of expansive awareness, peace, and often unconditional love. Most importantly, these experiences are associated with transformational changes that appear to persist and even grow over the coming months and years.

\section{Summary}

In this article we have discussed the research data on transformational changes associated with STEs such as near-death, psilocybin, or meditative experiences of cosmic consciousness. Despite their different etiologies, these three STEs appear to have attributes that are common to a broad range of mystical experiences, including an experience of expanded awareness that is normally hidden. In addition, all three appear to be associated with profound and lasting transformations in the lives of the experiencer. Finally, these three experiences appear to share some common neural correlates. In all three, there is a reduction in neural activity in the major centers of the brain, includ- 
ing the Default Mode Network which is the foundation of egoic stories and the narrative related to oneself and the world in which one lives. Reduced neural activity in areas of the brain that normally act as a filter or reducing valve mechanism opens the capacity to expanded awareness.

As Frederick Barrett and Griffiths (2018) noted, this intriguing overlap in the neural activity that occurs in both hallucinogen- and meditation-inspired STEs suggests the possibility that these neural correlates could support a common model for all mystical experiences. The stilling of brain activity in the DMN appears to reduce the filtering networks and may enhance novel interactions in other areas of the brain, enabling access to a higher awareness, a sense of unity consciousness. This experience often leads to a transformation, including engagement in spiritual practices like meditation, that continue to transform one's world view and lead to heightened experience of love, joy, and compassion for both oneself and one's fellow beings on this planet Earth.

\section{References}

Barrett, F. S., \& Griffiths, R. R. (2018). Classic hallucinogens and mystical experiences: Phenomenology and neural correlates. Current Topics Behavioral Neuroscience, 36, 393-430.

Brewer, J. A., Worhunsky, P. D., Gray, J. R., Tang, Y. Y., Weber, J., \& Kober, H. (2011). Meditation experience is associated with differences in default mode network activity and connectivity. Proceedings of the National Academy of Sciences USA, 108(50), 20254-20259.

Broadbent, D. E. (1958). Perception and communication. Pergamon Press.

Carhart-Harris, R. L., Erritzoe, D., Williams, T., Stone, J. M., Reed, L. J., Colasanti, A., Tyacke, R. J., Leech, R., Malizia, A. L., Murphy, K., Hobden, P., Evans, J., Feilding, A., Wise, R. G., \& Nutt, D. J. (2012). Neural correlates of the psychedelic state as determined by fMRI studies with psilocybin. Proceedings of the National Academy of Sciences USA, 109(6), 2138-2143.

Carhart-Harris, R. L. \& Friston, K. J. (2010). The default-mode, ego-functions and free-energy: A neurobiological account of Freudian ideas. Brain, 133(Pt 4), 1265-1283. https://doi.org/10.1093/brain/awq010

Condon, P., Desbordes, G., Miller W. B., \& DeSteno, D. (2013). Meditation increases compassionate responses to suffering. Psychological Science, 24, 2125 $-2127$.

Fredrickson, B. L., Cohn, M. A., Coffey, K. A., Pek, J., \& Finkel, S. M. (2008). Open hearts build lives: positive emotions, induced through lovingkindness meditation, build consequential personal resources. Journal of Personality and Social Psychology, 95(5), 1045-1062.

Greyson, B. (2003). Incidence and correlates of near-death experiences in a cardiac care unit. General Hospital Psychiatry, 25, 269-276. 
Greyson, B. (2014). Congruence between near-death and mystical experience. International Journal for the Psychology of Religion, 24, 298-310.

Greyson, B., \& Khanna, S. (2014). Spiritual transformation following near-death experiences. Spirituality in Clinical Practice, 1, 43-55.

Hood, R. W. J., Morris, R. J., \& Watson, P. J. (1990). Quasi-experimental elicitation of differential report of religious experience among intrinsic and indiscriminately pro-religious types. Journal for the Scientific Study of Religion, 29(2), 164-172.

Hood, R. W. J. (2009). Mysticism. In R. W. J. Hood, P. C. Hill, \& B. Spilka (Eds.), The psychology of religion (4th ed.). Guilford Press.

James, W. (1958). The varieties of religious experience. Mentor. (Original work published 1902).

Kason, Y. (1994). Farther shores: Exploring how near-death, kundalini, and mystical experiences can transform ordinary lives. HarperCollins.

Kason, Y. (2019). Touched by the light: Exploring spiritually transformative experiences. Dundurn.

Kastrup, B.. \& Kelly, E. F. (2018). Misreporting and confirmation bias in psychedelic research: What do images of the brain under psychedelics really tell us about its relation to the mind? Scientific American, Blog, Sept. 3, 2018.

Kelly, E. F., Kelly, E. W., Crabtree, A., Gauld, A., Grosso, M., \& Greyson, B. (2007). Irreducible mind: Toward a psychology for the 21st century. Rowman \& Littlefield.

Khanna, S., \& Greyson, B. (2014). Near-death experiences and spiritual wellbeing. Journal of Religion and Health, 53(6), 1605-1615.

Khanna, S., \& Greyson, B. (2014). Daily spiritual experiences before and after near-death experiences. Psychology of Religion and Spirituality, 6, 302-309.

Kraehenmann, R., Preller, K. H., Scheidegger, M., Pokorny,T., Bosch, O. G., Seifritz, E., \& Vollenweider, F. X. (2015). Psilocybin-induced decrease in amygdala reactivity correlates with enhanced positive mood in healthy volunteers. Biological Psychiatry, 78, 572-581. https://doi.org/10.1016/j.biopsych.2014.04.010

Luberto, C. M., Shinday, N., Song, R., Philpotts, L. L., Park, E. R., Fricchione, G. L., \& Yeh, G. Y. (2018). A systematic review and meta-analysis of the effects of meditation on empathy, compassion and prosocial behaviors. Mindfulness (NY), 9,708-724. https://doi.org/10.1007/s12671-017-0841-8

Musgrave, C. (1997). The near-death experience: A study of spiritual transformation. Journal of Near-Death Studies, 15, 187-201. https://doi.org/10.17514/ JNDS-1997-15-3-p187-201.

Myers, F. W. H. (1903). Human personality and its survival of bodily death (2 vols.). Longmans, Green.

Nicholas, C. R., Henriquez, K. M., Gassman, M. C., Cooper, K. M., Muller, D., Hetzel, S., Brown, R. T., Cozzi, N. V., Thomas, C., \& Hutson, P. R. (2018). High dose psilocybin is associated with positive subjective effects in healthy volunteers. Journal of Psychopharmacology, 32, 770-778. https://doi.org/10.1177/ 0269881118780713

Noyes, R., Jr., Fenwick, P., Holden, J. M., \& Christian, S. R. (2009). Aftereffects of pleasurable Western adult near-death experiences. In J. M. Holden, B. Greyson, \& D. James (Eds.), The handbook of near-death experiences: Thirty years of investigation (pp. 41-62). Praeger/ABC-CLIO.

Pagnoni, G., Cekic, M., \& Guo, Y. (2008). "Thinking about not thinking": Neural 
correlates of conceptual processing during Zen meditation, PLoS One, 3(9), e3083. https://doi.org/10.1371/journal.pone.0003083

Parnia, S. (2014). Death and consciousness-an overview of the mental and cognitive experience of death. Annals of the New York Academy of Sciences, 1330, 75-93. https://doi.org/10.1111/nyas.12582

Pennachio, J. (1986). Near-death experience as mystical experience. Journal of Religion and Health, 25, 64-72.

Ricard, M., Lutz, A., \& Davidson, R. J. (2014). Mind of the meditator. Scientific American, 311(5), 39-45.

Ross, S., Bossis, A., Guss, J., Agin-Liebes, G., Malone, T., Cohen, B., Mennenga, S. E., Belser, A., Kalliontzi, K., Babb, J., Su, Z., Corby, P., \& Schmidt, B. L. (2016). Rapid and sustained symptom reduction following psilocybin treatment for anxiety and depression in patients with life-threatening cancer: A randomized controlled trial. Journal of Psychopharmacology, 30(12), 11651180. https://doi.org/10.1177/0269881116675512

Sabom, M. (1982). Recollections of death. Harper \& Row.

Sartori, P. (2008). The near-death experiences of hospitalized intensive care patients. Edward Mellen.

Schwaninger, J., Eisenberg, P. R., Schechtman, K. B., \& Weiss, A. N. (2002). A prospective analysis of near-death experiences in cardiac arrest patients. Journal of Near-Death Studies, 20, 215-232. https://doi.org/10.17514/JNDS -2002-20-4-p215-232.

Stace, W. T. (1960). Mysticism and philosophy. MacMillan Press.

Swanson, L. R. (2018). Unifying theories of psychedelic drug effects. Frontiers in Pharmacology. https://doi.org/10.3389/fphar.2018.00172

Tassell-Matamua, N., \& Steadman, K. (2017). "I feel more spiritual": Increased spirituality after a near-death experience." Journal for the Study of Spirituality, 7, 35-49.

van Lommel, P., van Wees, R., Meyers, V., \& Elfferich, I. (2001). Near-death experience in survivors of cardiac arrest: a prospective study in the Netherlands. Lancet, 358(9298), 2039-2045.

Watts, A. (1970). Psychedelics and religious experience. In B. Aaronson \& H. Osmond (Eds.), Psychedelics: The uses and implications of hallucinogenic drugs (pp. 131-144). Anchor Books.

Woollacott, M. (2015). Infinite awareness: The awakening of a scientific mind. Rowman \& Littlefield.

Wulff, D. M. (2014). Mystical experiences. In E. Cardeña, S. J. Lynn, \& S. Krippner (Eds.), Varieties of anomalous experience: Examining the scientific evidence (2nd ed., pp. 369-408). American Psychological Association.

Zingrone, N. L., \& Alvarado, C. S. (2009). Pleasurable Western adult near-death experiences: Features, circumstances, and incidence. In J. M. Holden, B. Greyson, \& D. James (Eds.), The handbook of near-death experiences: Thirty years of investigation (pp. 17-41). Praeger/ABC-CLIO. 